Original Research Paper

\title{
Investigating the E-Learning Acceptance in Oman: Application of Structural Equation Modelling Approach
}

\author{
${ }^{1}$ Salim Amor Al-Hajri, ${ }^{2}$ Syed Ghayas and ${ }^{3}$ Abdelghani Echchabi \\ ${ }^{1,3}$ Department of Management Information Systems, Asharqiya University, Ibra, Oman \\ ${ }^{2}$ Department of Computer Information Sciences, Universiti Teknologi PETRONAS, Malaysia
}

\author{
Article history \\ Received: $12-10-2017$ \\ Revised: $18-12-2017$ \\ Accepted: 16-03-2018 \\ Corresponding Author: \\ Syed Ghayas \\ Department of Computer \\ Information Sciences, \\ Universiti Teknologi \\ PETRONAS, Malaysia \\ Email: syedghayas@ciit.net.pk
}

\begin{abstract}
Similar to many developing countries, Oman recognizes the importance of e-learning and Information Communication Technology (ICT) to enhance the higher education standards and compete in the global education markets. Many higher education organizations today expect elearning to add value to their organization and hence improve the economy by extending their educational services to students and other students who are not able to access them due to geographical distance limitation. His Majesty the Sultan Qaboos speech in 2008 adds further motivation for the development of the Information systems and technology in Oman by saying "Information technology and communications have now become the main elements that move forward the development process in this third millennium; therefore, we have afforded our attention to finding a national strategy to develop the skills and abilities of citizens in this domain with the aim of further developing e-government services". The Omani government has supported this process substantially through the development of telecom infrastructure and establishment of Information Technology Authority (ITA) to implement national IT infrastructure and supervise the implementation of digital Oman strategy. Although, there is high consensus in the higher educational literature that e-learning acceptance is vital for the competitive advantage of our organizations. Yet, there are still considerable gaps in our e-learning acceptance and understanding of a range of issues concerning both the conceptual and practical as the higher education in Oman is far behind in the development of e-learning acceptance. The lack of e-learning acceptance in the higher education has created problems for most organizations. Hence, this paper focuses on the investigation of the key factors that influence e-learning acceptance in Omani Universities. The study covered a sample of 800 respondents and applied structural equation modelling approach in the analysis. The findings indicated that the students are intending to use e-learning services. On the other hand, the findings revealed that the main variable that influence their behavior are perceived usefulness and perceived ease of use.
\end{abstract}

Keywords: E-learning, Oman, SEM, ICT

\section{Introduction}

Electronic communication and digital networks has played a major role in the economic development. Garrison (2011) supported this notion by stating that "Electronic communication and digital networks are transforming the way we work and are reshaping personal communication and entertainment".

In response to electronic communication and digital networks development, the higher education industry globally is challenged to accept the electronic learning (e-learning) as a medium to design and deliver effective learning experience for their students and teachers utilizing suitable software applications and communication network technologies.

Al-Hajri and Echchabi (2017) highlighted that "A strong educational system is important in every country because it can significantly support the economy through knowledgeable and experienced individuals. Changes in the educational system can play a major role in moving 
the economy forward and hence keeping up with globalization movement". Specifically, Garrison (2011), Engelbrecht (2005) and Selim (2005) identified four major benefits from e-learning as follows:

- Offering learner's knowledge with learning experiences

- Offering learner's convenience anywhere and anytime

- Offering learners with relative advantages

- Offering learners with a collaborative constructive transaction

In our today's global and competitive environment, modern electronic communication and digital networks are required to enhance our learning experience that is more flexible and responsive. Notwithstanding the development of modern electronic communication and digital networks technologies the Omani educational industry is still far behind in making significant changes in the use of e-learning technologies. In order to fulfil the role expected of educational industry in Oman, indeed higher education organizations must seriously consider accepting e-learning.

Despite the fact that e-learning acceptance is booming worldwide, higher education organizations in Oman are yet to accept e-learning seriously. Very Few universities have made modest effort to incorporate elearning in their universities to market their universities programs. The hesitance of e-learning acceptance by most universities and colleges suggests that Universities/colleges' management perceive the costs of e-learning acceptance is too high compared with desired benefits. In the case of high investment e-learning project this hesitance by university presidents can be interpreted with fear of the consequences of failure and hence students' dissatisfaction (Butterfield and Pendegraft, 2001). This means that the cost of delivering educational services is increasing compared to the low quality of delivery of university courses. Therefore, it is important for us to understand students' acceptance of e-learning so that Omani universities' presidents can design and delivery effective learning experience for their students and teachers.

The remaining part of the paper is organized as follows: Section two discusses the main studies in the area of E-learning acceptance as well as the research model. Section three briefly discusses the methodology and method applied for data analysis as well as the respondents' profile. Section four presents the survey results and section five concludes the paper with some recommendations for future studies.

\section{Literature Review}

Many authors (Selim, 2007; Ruiz et al., 2006; Ruth and Mayer, 2011) define e-learning as the use of modern electronic channels to design and deliver collaborative educational services to enhance knowledge and performance effectively.

Further definition is given to e-learning by Engelbrecht, (2005, p218) as "the use of electronic media (the Internet, DVD, CD-Rom, videotapes, television, cell phones, etc.) for teaching and learning at a distance. It also provides learners with the convenience of learning anywhere, anytime".

E-learning is also called online learning, Web-based learning and Internet-based learning. Basically, there are two known types e-learning, namely: (1) Web-based learning and (2) computer-based learning. Web-based learning is the process of designing and delivering educational services to educators and learners on campus utilizing the Intranet and computer-based learning is the process of designing and delivering educational services to educators and learners off campus utilizing the Internet.

A similar concept is the blended learning which is an education program that combines online digital media with traditional classroom methods. It requires the physical presence of both teacher and student, with some elements of student control over time, place, path, or pace. For example, learners will be required to be on campus for classes as well as use the Web-based learning for online tutorials. It combines both classes and online learning.

E-learning technologies promised both educators and learners benefits associated with e-learning technology acceptance including simplicity, convenience and usefulness. However, Engelbrecht (2005) and Garrison (2011) have recently questioned the ability of e-learning to design and deliver these benefits and the revolution it promised in the educational industry.

Engelbrecht (2005) examined the post-graduate students' experience of e-learning program. His study focused in three criteria: The use of technology, the learning design and flexibility of the program. He argued that "the choice of technologies, the outsourcing of teaching services and the program facilitators teaching approach emulate the face-to-face tax program and therefore still support a teacher-centered teaching and learning approach" (p. 217).

The aim of Engelbrecht's study was to evaluate the implementation of an e-learning Master program in in South Africa. From an analysis of 71 responses obtained from a closed questionnaire sent to the private e-mail addresses of students, Engelbrecht reported that there is a lack of convenient learning environment and interactive learning. Furthermore, the system was not redesigned to promote student-centered online learning and hence measuring learning experience quality pose a challenge. In addition, the teachers and facilitators are not trained to apply online teaching strategies.

Notwithstanding, the wide spread of e-learning acceptance globally, Garrison (2011) questioned the elearning by stating that "to realize the potential of e- 
learning as an open but cohesive system, it is essential that we rethink our pedagogy. Education is about ideas not facts". He further argued by saying that "students in higher education are not receiving the educational experience they need to develop the critical and selfdirected higher education skills required for long life learning." (p53). He suggested that for "e-learning to have a significant place in education it must prove that it is more than a medium to conveniently access content". That means e-leaning of today must demonstrate full interactivity between students and teachers in order to get full benefit.

In contrast, several authors (Al-Senaidi et al., 2009; Bada and Khazali, 2006) noted the potential use of computer technology in education industry to improve teaching and learning quality. However, the educational industry in Oman is not able to optimize their existing elearning platforms. This can be explained by the lack of infrastructures that incorporate e-learning in their education systems. Given the prevalence of e-learning technology acceptance by the educators and learners in developed countries, the reason for the lack of such an innovation in developing countries such as Oman is a fruitful research question. In an attempt to answer the question raised above, four existing theories were examined, namely, the Theory of Reasoned Action (TRA), the Theory of Planned Behavior (TPB), the Technology Acceptance Model (TAM) and Diffusion of Innovations Theory (DIT).

The Theory of Reasoned Action (TRA) was developed by Fishbein and Ajzeni (1975). Subsequently, in 1980, they have used empirical evidence to support the validity and reliability of their theory to refine their model. They further elucidated that the Behavior Intention (BI) of a person is determined by their attitude and subjective norm.

Afterwards, Ajzen (1991) observes some problems with the TRA. He assumes that a person's behavior is controlled by the person himself. Based on this assumption he altered the previous model and called it Theory of Planned Behavior (TPB). In the TPB, he included another construct called Perceived Behavioral Control and referred it to the "presence or absence of requisite resources and opportunities" (Ajzen and Madden, 1986, p. 457).

Subsequently, Davis (1986) and Davis et al. (1989) established another theory called Technology Acceptance Model (TAM). He developed TAM to assess the effects of system characteristics on users' computer technology acceptance. The author postulates that behavioral intention to use a computer technology is determined by two major factors namely, perceived usefulness and perceived ease of use.

Furthermore, the Diffusion of Innovation Theory (DIT) was developed by Rogers (1995). He describes his theory as "the process by which an innovation is communicated through certain channels over time among the members of social systems" (p. 5). The author postulates that the adoption of an innovation is influenced by the five perceived innovation characteristics namely, relative advantage, compatibility, complexity, trialability and observability.

In this study, four constructs were identified from previous studies that were relating to e-learning acceptance. Perceived Ease of Use (PEOU) and Perceived Usefulness (PU) (Davies, 1989; Igbaria et al., 1997) and two more constructs were noted in previous studies (Arbaugh, 2002; Arbaugh and Duray, 2002) namely, perceived Infrastructure and perceived System Quality (PISQ) and Perceived computer and Internet self-efficacy (PCIS) (Brown, 2002; Grandon et al., 2005; Ong and Lai, 2006).

It is noteworthy that several studies (Hong et al., 2003; Poon et al., 2004; Selim, 2007) highlighted the importance of students' and instructors' characteristics, organization's information technology infrastructure and organization's technical support. However, in this study, students' characteristics are the main focus.

Therefore, these four dimensions were explored from the perspective of students that are the target and will be jointly examined to answer the question: What are the factors that can potentially influence the acceptance of elearning in the educational industry in Oman?

H1: Perceived usefulness has a positive influence on the students' intention to use e-learning

H2: Perceived ease of use has a positive influence on the students' intention to use e-learning

H3: Perceived infrastructure and system quality has a positive influence on the students' intention to use e-learning

H4: Perceived computer and internet self-efficacy has a positive influence on the students' intention to use e-learning

\section{Methodology}

The current study focuses on the university students in Oman. The target sample size was 800 respondents determined through the previous similar studies in this area (Hong et al., 2003; Poon et al., 2004; Selim, 2007). Out of the distributed questionnaires only 680 were properly and completely filled up and returned. Thus, a response rate of 85 per cent was achieved.

The survey questionnaire was designed to collect information about the perception of the university students towards the attributes of e-learning as well as their intention to adopt and/or continue using it in their future operations. For measuring this information, Likert type scaling was used $(1=$ Strongly agree and $5=$ Strongly disagree). 25 items were listed in this section 
and most of them were derived from the previous studies conducted in other countries as highlighted above, as well as from current education information technology literature with necessary adaptations made for the specific context of this study. The second section of the questionnaire explored information about respondents' profile, i.e. gender, age, education level, study mode, etc. The questionnaire was made in English and was subsequently translated into Arabic and distributed in both versions.

The data gathered were subsequently analyzed using structural equation modelling and one sample t-test. The choice of this technique was inspired from Hair et al. (2010) as well as from similar studies conducted in this area. It is worth mentioning that the analysis was done through AMOS 18 and SPSS 18.

As presented in Table 1 below, the respondents' profiles (Male and female) in terms of demographic characteristic are very similar in both groups. Specifically, the female profile is dominant in the respondents' profile aged range between 20 to 30 years.

\section{Results}

\section{Reliability and Validity Measures}

Prior to the structural model estimation through Structural Equation Modelling (SEM), a basic requirement is the analysis of the model validity. The latter is made of four main elements, namely, convergent validity, discriminant validity, face validity and nomological validity.

Convergent validity refers to the requirement that the items measuring a given construct should share a high proportion of common variance. There are several tools to assess convergent validity, including Average Variance Extracted (AVE), factor loadings, as well as reliability measures (Cronbach Alpha for this study) (Hair et al., 2010). Accordingly, it is suggested that a Cronbach Alpha greater or equal to 0.6 is acceptable, similarly and acceptable level of AVE and factor loadings should be 0.5 and above.

In this regard, Table 2 shows that the Cronbach Alpha values are ranging between 0.657 and 0.836 . Furthermore, the AVE values range between 0.51 and 0.61 . Hence, all the requirements for convergent validity are met, since all the factor loadings are also greater than 0.5 . Thus, convergent validity is achieved in this model.

In addition, discriminant validity refers to the requirement that each construct in the model is distinct from the remaining constructs. There are different ways to assess discriminant validity. In this study the correlation between constructs will be fixed to 1 and the fit indices for the baseline and restricted models will then be compared. At this level, discriminant validity is achieved if the difference in fit indices between the two models is significant. In this regard, the results in Table 3 show a Chi square value of 558.535 and 242 degrees of freedom for the baseline model and a Chi square value of 909.389 and 252 degrees of freedom for the restricted models. This amounts to a Chi square difference of 350.854 and degrees of freedom difference of 10 . By comparing the Chi square difference with the tabulated Chi square value corresponding to a degree of freedom of 10 and a confidence margin of 0.05 , namely, 18.31 , it can be concluded that the fit indices for the baseline and restricted model are significantly different. Hence, discriminant validity is achieved by this model. Besides these two validity measures, face validity and nomological validity were also analyzed by consulting the experts in this field, as well as the previous studies.

Finally, the results indicate that the model's Comparative Fit Index (CFI) is 0.929 and RMSEA value is 0.048 . These values are acceptable values for both indicators (Broyles et al., 2010; Singh et al., 2011; Kim and Forsythe, 2010), hence, the overall model is validated.

\section{Hypotheses Testing}

In order to test the hypotheses posited above, the path analysis using SEM is applied for the first four hypotheses, while t-test is used to test the fifth hypothesis. In this regard, the mean values in Table 4 indicate high t-values for all the variables including behavioral intention, with significant probability values.

Hence, hypothesis 5 is rejected. This mainly indicates that the respondents are satisfied with their e-learning experience and are enthusiastic about it and intend to progress in their study through e-learning. This is translated though their appreciation of the usefulness and ease of use of e-learning which is a prerequisite for regularly using it in their daily studies. Furthermore, the students perceive that their respective universities possess the required infrastructure and system quality necessary for the daily running of the e-learning system.

In addition to the t-test results above, a one-way ANOVA test has also been conducted to identify possible differences across demographic groups regarding all the model dimensions. Regarding perceived usefulness, the results indicate that there is a significant difference between education groups, where higher education students perceive e-learning to be more useful compared to other students' levels. Furthermore, there is a significant difference in perceived usefulness depending on the internet access type whereby students accessing internet at work perceive e-learning to be more useful compared to other groups. Finally, there is a significant difference in perceived usefulness across computer knowledge levels. In this regards, students with excellent level of computer knowledge perceived elearning to be more useful compared to other levels. 
Table 1: Profile analysis

\begin{tabular}{|c|c|c|}
\hline Demographics & Categories & Percentage \\
\hline \multirow[t]{2}{*}{ Gender } & Male & 28.2 \\
\hline & Female & 71.8 \\
\hline \multirow[t]{5}{*}{ Age } & Less than 20 years & 27.6 \\
\hline & 20 to 30 years & 65.0 \\
\hline & 31 to 40 years & 5.6 \\
\hline & 41 to 50 years & 1.8 \\
\hline & More than 50 years & - \\
\hline \multirow[t]{5}{*}{ Education level } & Secondary School & 17.1 \\
\hline & Diploma & 20.1 \\
\hline & High diploma & 14.4 \\
\hline & Bachelor's degree & 45.6 \\
\hline & Higher education & 2.8 \\
\hline \multirow[t]{5}{*}{ Occupation } & Government student & 71.5 \\
\hline & Private student & 11.4 \\
\hline & Private student/EMPLOYED & 7.5 \\
\hline & Private student/ Unemployed & 6.6 \\
\hline & Private student/self-employed & 2.9 \\
\hline \multirow[t]{4}{*}{ Income } & Less than 300 & 66.8 \\
\hline & Between 300 and 600 & 24.8 \\
\hline & Between 601 and 1200 & 6.3 \\
\hline & Above 1200 & 2.1 \\
\hline \multirow[t]{5}{*}{ Internet Access } & Home & 44.4 \\
\hline & University & 43.8 \\
\hline & Work/office & 5.9 \\
\hline & Internet cafe & 2.1 \\
\hline & Not Available & 3.8 \\
\hline \multirow[t]{5}{*}{ Computer knowledge } & Poor & 3.2 \\
\hline & Moderate & 21.6 \\
\hline & Good & 27.1 \\
\hline & Very good & 30.7 \\
\hline & Excellent & 17.4 \\
\hline
\end{tabular}

Table 2: Convergent validity measures

\begin{tabular}{lll}
\hline Constructs & Cronbach Alpha & AVE \\
\hline Perceived usefulness & 0.698 & 0.52 \\
Perceived ease of use & 0.755 & 0.51 \\
Perceived infrastructure and system quality & 0.657 & 0.54 \\
Perceived computer and internet self-efficacy & 0.676 & 0.56 \\
Behavioural intention & 0.836 & 0.61 \\
\hline
\end{tabular}

Table 3: Discriminant validity measures

\begin{tabular}{llr}
\hline Elements & Chi square & DF \\
\hline Baseline model & 558.535 & 242 \\
Restricted model & 909.389 & 252 \\
Change & 350.854 & 10 \\
\hline
\end{tabular}

Table 4: Descriptive analysis and t-test

\begin{tabular}{llll}
\hline Constructs & Mean & $\mathrm{t}$ & Standard deviation \\
\hline Perceived usefulness & 1.953 & $-41.7^{* * *}$ & 0.648 \\
Perceived ease of use & 2.131 & $-34.53^{* * *}$ & 0.653 \\
Perceived infrastructure and system quality & 2.274 & $-24.74^{* * *}$ & 0.760 \\
Perceived computer and internet self-efficacy & 2.274 & $-24.74^{* * *}$ & 0.760 \\
Behavioural intention & 2.154 & $-28.20^{* * *}$ & 0.778 \\
\hline
\end{tabular}

****efer to significant t-test at $1 \%$

Regarding perceived ease of use, the results indicated that there is a difference across groups depending on their internet access types. In this regards, students that access internet at work perceive e-learning to be easier to use compared to other groups. In addition, there is a difference in ease of use 
perception depending on the computer knowledge whereby as expected, students that have excellent level of computer knowledge perceive e-learning to easier to use compared to students from other levels.

On the other hand, concerning infrastructure and system quality, the results showed a difference in perception across gender, whereby the male respondents perceive that their respective universities have better infrastructure and system quality, compared to the female respondents. In addition, a significant difference is observed across age groups. In this regards, respondents aged between 41 and 50 years old perceive the infrastructure and system quality of their respective universities better compared to other groups.

Furthermore, there is a significant difference in perception across education groups whereby again the higher education students perceive better the infrastructure and quality system compared to other groups. Moreover, a significant difference was identified relating to students' type, whereby employed private students perceive the infrastructure and system quality of their respective universities better compared to other groups. In addition, a significant difference was identified depending on the income level where respondents with income ranging from OMR601 to OMR1, 200 perceive the infrastructure and system quality of their respective universities better. Furthermore, students that access internet at work perceive the infrastructure and system quality better than other groups.

Finally, students that have excellent computer knowledge are more appreciative of the infrastructure and system quality compared to students with lower computer level. With regards to computer and internet self-efficacy, a significant difference is identified across all the categorical variables, namely, gender, age, educational level, occupation, income level, internet access type and computer knowledge level. Specifically, male respondents perceive themselves to be more computer and internet efficient compared to the female respondents. Similarly, the respondents aged between 41 and 50 years old perceive themselves to be more computer and internet self-efficient compared to other age groups.

In higher education, students perceive themselves to be more computer and internet self-efficient compared to other education level groups. On the other side, private employed students perceive themselves to be more computer and internet self-efficient compared to other groups. Furthermore, the respondents with income ranging from OMR 601 to OMR 1,200 perceive themselves to be more computer and internet self-efficient compared to other income level groups. Moreover, the students accessing internet at work perceive themselves to be more computer and internet self-efficient compared to other groups.

Finally, the students with excellent level of computer and internet knowledge also perceive themselves to be more computer and internet self-efficient compared to other groups.

In summary, with regards to behavioral intention, a significant difference was identified across the students' type as well as computer knowledge level. Specifically, private employed students are keener to use e-learning compared to other types of students. In addition, students with excellent level of computer and internet knowledge are more inclined to use e-learning to progress in their studies compared to other groups.

The path analysis is summarised in Table 5 and Fig. 1 . The results indicate that perceived usefulness has a significant positive impact on the intention to use elearning. Hence, hypothesis 1 is supported. This is in line with the findings of Davies (1989). This implies that the students are appreciative of the usefulness of e-learning in terms of improved learning and research performance and more importantly its significance in reducing their travelling and management expenses.

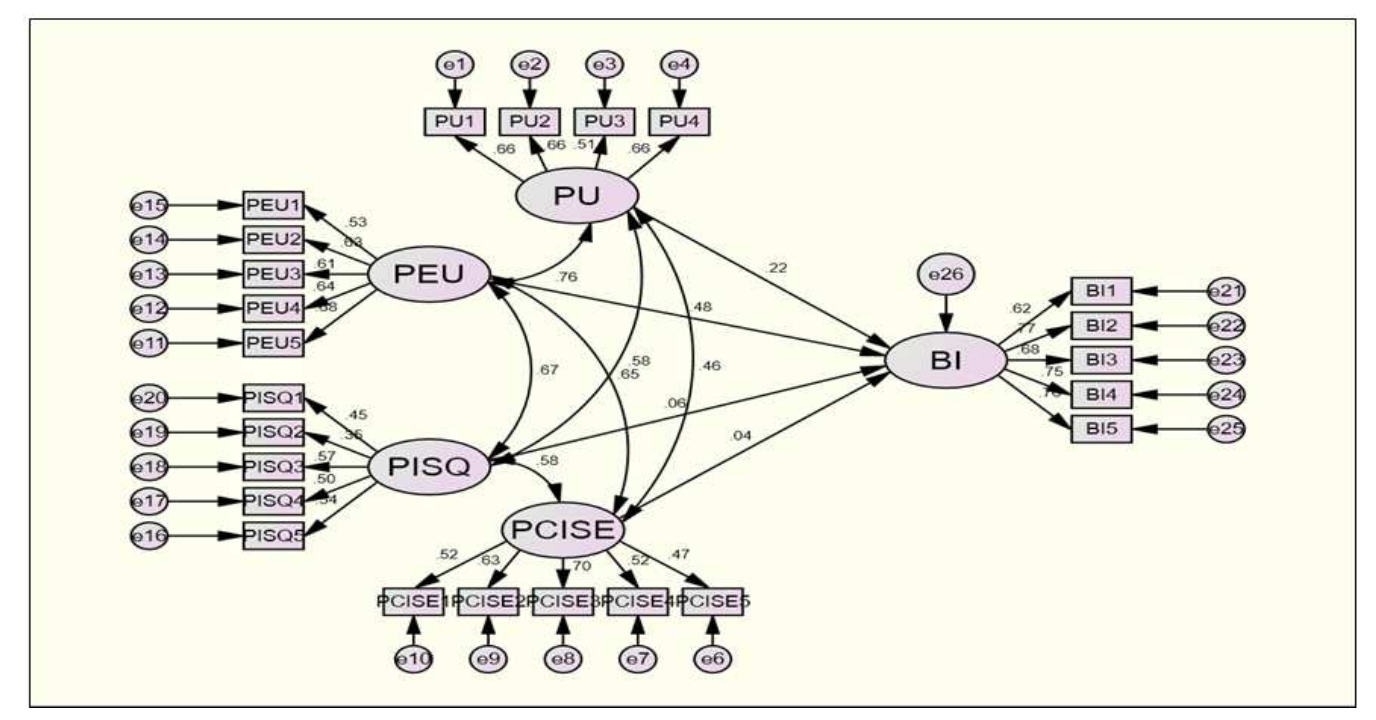

Fig. 1: Structural model 
Table 5: Standardized total effects

\begin{tabular}{lllll}
\hline & $\begin{array}{l}\text { Perceived } \\
\text { usefulness }\end{array}$ & $\begin{array}{l}\text { Perceived } \\
\text { ease of use }\end{array}$ & $\begin{array}{l}\text { Perceived infrastructure } \\
\text { and system quality }\end{array}$ & $\begin{array}{l}\text { Perceived computer and } \\
\text { internet self-efficacy }\end{array}$ \\
\hline Behavioural intention & $0.298^{* * *}$ & $0.498^{* * *}$ & 0.073 & 0.043 \\
\hline
\end{tabular}

Furthermore, the perceived ease of use is also found to have a significant positive influence on the intention to use e-learning. Hence, hypothesis 2 is supported. This is in line with the findings of Davies (1989).

On the other hand, perceived infrastructure and system quality as well as the perceived computer and internet selfefficacy have no significant impact on the intention to use e-learning. Hence, hypotheses 3 and 4 are rejected.

Thus, among the four explanatory variables initially included, only two are found to be significantly influencing the intention of the Omani students to adopt e-learning instead of traditional learning methods.

\section{Discussions and Conclusion}

The objective of the current study was two-fold i.e., to explore the intention of the Omani students to use elearning and to determine the variables that may influence it. Overall, the results indicated that the students are intending to use e-learning services. On the other hand, the findings revealed that the main variable that influence their behaviour are perceived usefulness and perceived ease of use.

These findings have significant implications for the theory, for the policy makers and regulators as well as for the practitioners. Particularly, this study is an extension of the innovations diffusion theory and technology acceptance model to a different setting and to a different area of study that has been poorly studied previously; hence this study proves the applicability of this theory in this new context. Similarly, the current study provides insights to the practitioners and policymakers on the important dimensions to be emphasised to ameliorate the e-learning usage in Oman and similar settings.

The current study has a number of limitations that should be taken into account in the future studies in this area. Firstly, the sample size is relatively limited, though accurately calculated, hence the results cannot be generalised to the whole Omani population. Thus, the future studies are recommended to select a larger and more representative sample size, in order to generalise the results to the whole country. The future studies are also recommended to extend these findings to other contexts and preferably using other models as well.

\section{Acknowledgement}

The authors thank the reviewers for their valuable comments and suggestions for improving the quality of this paper.

\section{Author's Contributions}

Salim Amor Al-Hajri: Design, experimentation, collection of data, drafting.

Syed Ghayas: Analysis and interpretation of data, reviewing.

Abdelghani Echchabi: Analysis and interpretation of data, reviewing.

\section{Ethics}

This article is original and corresponding authors confirm that this manuscript have no ethical issues involved.

\section{References}

Ajzen, I. and T. Madden, 1986.and Prediction of goaldirected behavior: Attitudes, Intentions and perceived behavioral control. J. Experimental Social Psychol., 22: 453-74.

Ajzen, I., 1991. The theory of planned behavior. Organizational Behav. Human Decision Proc., 50: 179-211. DOI: 10.1016/0749-5978(91)90020-T

Al-Hajri, S. and A. Echchabi, 2017. Exploring factors affecting successful acceptance of e-learning: Innovative technology solutions in Oman. Int. J. Bus. Administration Manage. Res., 3: 1-5.

DOI: 10.24178/ijbamr.2017.3.1.01

Al-Senaidi, S., L. Lin and J. Poirot, 2009. Barriers to adopting technology for teaching and learning in Oman. Comput. Educ., 53: 575-590.

DOI: 10.1016/j.compedu.2009.03.015

Arbaugh, J., 2002. Managing the on-line classroom: A study of technological and behavioural characteristics of web-based MBA courses. J. High Technol., 13: 203-223.

DOI: $10.1016 / \mathrm{S} 1047-8310(02) 00049-4$

Arbaugh, J. and R. Duray, 2002. Technological and structural characteristics, student learning and satisfaction with web-based courses - an exploratory study of two online. Manage. Learn., 33: 291-311. DOI: $10.1177 / 1350507602333003$

Bada, J. and B. Khazali, 2006. An empirical study on education strategy to e-learning in a developing country. Proceedings of the 4th IEEE International Workshop on Technology for Education in Developing Countries, Jul. 10-12, IEEE Xplore Press, Iringa. DOI: 10.1109/TEDC.2006.1 
Brown, I., 2002. Individual and technological factors affecting perceived ease of use of web-based learning technologies in a developing country. Electron. J. Inform. Syst. Develop. Countries, 9: 1-15.

Broyles, A., T. Leingpitul, R. Ross and B. Foster, 2010. Brand equity's antecedent/consequence relationships in cross-cultural settings. J. Product Brand Manage., 19: 159-169. DOI: $10.1108 / 10610421011046148$

Butterfield, J. and N. Pendegraft, 2001. Analyzing information system investments: A game-theoretic approach. Inform. Syst. Manage., 18: 73-82. DOI: $10.1201 / 1078 / 43196.18 .3 .20010601 / 31293.10$

Davies, F.D., 1989. Perceived usefulness, perceived ease of use and user acceptance of information technology. MIS Q., 13: 319-340. DOI: $10.2307 / 249008$

Davis, F., 1986. 'A technology acceptance model for empirically testing new end-user information systems: Theory and results'. PhD Thesis, MIT.

Davis, F., R. Bagozzi and P. Warshaw, 1989. User acceptance of computer technology: A comparison of two theoretical models. Manage. Sci., 35: 982-1003. DOI: $10.1287 / \mathrm{mnsc} .35 .8 .982$

Engelbrecht, M., 2005. Adapting to changing expectations: Postgraduate students' experience of an e-learning tax program. Comput. Educ., 45: 217-229. DOI: 10.1016/j.compedu.2004.08.001

Fishbein, M. and I. Ajzen, 1975. Belief, Attitude, Intention and Behavior: An Introduction to Theory and Research. 1st Edn., Addison-Wesley, Reading, ISBN-10: 0201020890, pp: 578.

Garrison, D., 2011. E-Learning in the 21st Century: A Framework for Research and Practice. 2nd Edn., Routledge Falmer, London.

Grandon, E., K. Alshare and O. Kwun, 2005. Factors influencing student intention to adopt online classes: A cross-cultural study. J. Comput. Sci. College, 20: 46-56.

Hair, J., W. Black, B. Babin and R. Anderson, 2010. Multivariate Data Analysis. 7th Edn, Prentice Hall, Upper Saddle. N. J.

Hong, K., K. Lai and D. Holton, 2003. Students' satisfaction and perceived learning with a web-based course. J. Educ. Technol. Society, 6: 116-124

Igbaria, M., N. Zinatelli, P. Cragg and A. Cavaye, 1997. Personal computing acceptance factors in small firms: A structural equation model. MIS Q, 21; 279-305. DOI: $10.2307 / 249498$
Kim, J. and S. Forsythe, 2010. Factor affecting adoption of product virtualisation technology for online consumer electronics shopping. Int. J. Retail Distribution Manage., 38: 190-204. DOI: $10.1108 / 09590551011027122$

Ong, C. and J. Lai, 2006. Gender differences in perceptions and relationships among dominants of elearning acceptance. Comput. Human Behav., 22: 816-829. DOI: 10.1016/j.chb.2004.03.006

Poon, W., K. Low and D. Yong, 2004. A study of WebBased Learning (WBL) environment in Malaysia. Int. J. Educ. Manage., 18: 374-385. DOI: $10.1108 / 09513540410554031$

Rogers, E., 1995. Diffusion of Innovation. 4th Edn., Simon and Schuster, New York.

Ruiz, J., M. Mintzer and R. Leipzig, 2006. The impact of e-learning in medical education. Acad. Med., 81: 207-212.

Ruth, C. and R. Mayer, 2011. E-Learning and the Science of Instruction: Proven Guidelines for Consumers and Designers of Multimedia Learning. 1st Edn., John Wiley and Sons, New Jersey.

Selim, H., 2005. Videoconferencing-mediated instruction: Success model. J. Distance Educ. Technol., 3: 62-80. DOI: 10.4018/jdet.2005010104

Selim, H., 2007. Critical success factors for e-learning acceptance: Confirmatory factor models. Comput. Educ., 49: 396-413. DOI: 10.1016/j.compedu.2005.09.004

Singh, R., H. Sandhu, B. Metri and R. Kaur, 2011. Organisational performance and retail challenges: A structural equation approach. Business, 3: 159-168. DOI: 10.4236/ib.2011.32022 